\title{
A linguagem verbal e visual em uma passagem de $M s$. Marvel, Volume 1: No normal e em suas traduções para o português brasileiro e europeu
}

\section{Verbal and visual language in an excerpt of Ms. Marvel, Volume 1: No normal and its translations to Brazilian and European Portuguese}

\author{
Márcia Tavares CHICO* \\ Roberta Rego RODRIGUES ${ }^{* *}$
}

\begin{tabular}{|c|c|}
\hline $\begin{array}{l}\text { RESUMO: Ao lançar mão da Estilística } \\
\text { Tradutória, da Tradução Intermodal, da } \\
\text { Linguística Sistêmico-Funcional, da } \\
\text { Gramática do Design Visual e dos } \\
\text { Estudos das Cores, este artigo tem por } \\
\text { objetivo investigar a linguagem verbal e } \\
\text { não-verbal em um excerto de Ms. Marvel, } \\
\text { Volume 1: No normal e em duas traduções } \\
\text { para o português brasileiro e europeu, } \\
\text { consoante a metafunção interpessoal. } \\
\text { Utilizaram-se cinco abas de uma planilha } \\
\text { em formato XSL. Nas três primeiras abas, } \\
\text { relativas à linguagem verbal, foram } \\
\text { usadas as categorias Fornecimento, } \\
\text { Demanda, Informação, Bens e Serviços, } \\
\text { Modalização e Modulação. Na quarta aba, } \\
\text { relacionada à linguagem não-verbal, } \\
\text { foram empregadas as categorias Oferta, } \\
\text { Demanda e Termos Básicos de Cores. Na } \\
\text { quinta aba, também vinculada a essa } \\
\text { linguagem, foram identificados os } \\
\text { Termos Básicos de Cores mais frequentes } \\
\text { nos painéis selecionados. Houve a }\end{array}$ & $\begin{array}{l}\text { ABSTRACT: This article aims to } \\
\text { investigate verbal and non-verbal } \\
\text { language in an excerpt from Ms. Marvel, } \\
\text { Volume 1: No Normal and in two of its } \\
\text { translations, one to Brazilian Portuguese } \\
\text { and the other one to European } \\
\text { Portuguese. To do so, we use } \\
\text { Translational Stylistics, Intermodal } \\
\text { Translation, Systemic Functional } \\
\text { Linguistics, Visual Design Grammar, and } \\
\text { Colour Studies, in accordance to the } \\
\text { interpersonal metafunction. We used a } \\
\text { five-tabbed spreadsheet. The first three } \\
\text { tabs encompass the use of verbal } \\
\text { language in the categories: Offer, } \\
\text { Demand, Information, Goods and } \\
\text { Services, Modalization, and Modulation. } \\
\text { The fourth tab encompasses non-verbal } \\
\text { language in the categories: Offer, } \\
\text { Demand, and Basic Colour Terms. The } \\
\text { fifth tab is also concerned with non-verbal } \\
\text { language and identifies the most frequent } \\
\text { Basic Colour Terms found in the selected }\end{array}$ \\
\hline
\end{tabular}

\footnotetext{
* Doutoranda em História e bacharelanda em Letras Tradução Inglês/Português pela UFPel. ORCID http://orcid.org/0000-0001-7574-9655. marciatch@gmail.com

** Doutora. Professora Associada, área de Tradução/CLC/UFPEL. ORCID: https://orcid.org/0000-0002$\underline{1580-1789}$. roberta.rego@ufpel.edu.br
} 


\begin{tabular}{|c|c|}
\hline $\begin{array}{l}\text { icação das categorias que } \\
\text { am "sim" através de uma função } \\
\text { grama Microsoft Excel nas quatro } \\
\text { as abas. No que concerne à quinta } \\
\text { quantificação dos Termos Básicos } \\
\text { res mais recorrentes foi feita } \\
\text { Imente. Os resultados apontam } \\
\text { tocante às categorias utilizadas } \\
\text { linguagem verbal, o texto-fonte e } \\
\text { s-alvo são idênticos. Os resultados } \\
\text { indicam que, em relação aos } \\
\text { a Oferta é mais frequente que a } \\
\text { da, coadunando com os dados da } \\
\text { em verbal, em que o } \\
\text { mento se manifesta com mais } \\
\text { idade. Pode-se concluir que, } \\
\text { à linguagem verbal, encontram-se } \\
\text { ças entre o texto-fonte e os textos- } \\
\text { b uma perspectiva microtextual; e } \\
\text { n grande parte, observou-se uma } \\
\text { ância entre os modos semióticos }\end{array}$ & $\begin{array}{l}\text { panels. In the first four tabs, the categories } \\
\text { marked as "yes" through a Microsoft } \\
\text { Excel function were later quantified. } \\
\text { However, for the fifth tab, the } \\
\text { quantification was carried out manually. } \\
\text { The results show that the source text and } \\
\text { target texts are identical when it comes to } \\
\text { the verbal language categories. The } \\
\text { results also show that, for non-verbal } \\
\text { language, Offer is more frequent than } \\
\text { Demand, which matches the results for } \\
\text { verbal language. We can conclude that, } \\
\text { for verbal language, the differences } \\
\text { between the source text and the target } \\
\text { texts are micro-textual. We could observe } \\
\text { a consonance between the verbal and } \\
\text { visual semiotic modes in the selected } \\
\text { excerpt. }\end{array}$ \\
\hline 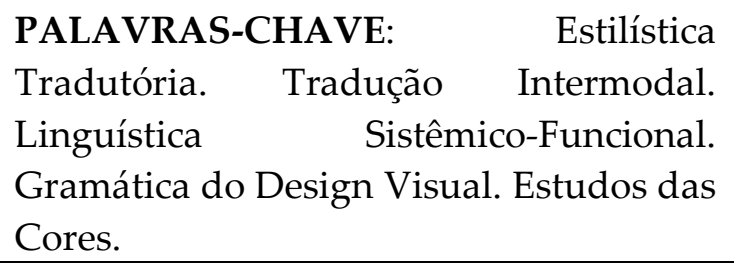 & $\begin{array}{l}\text { KEYWORDS: Translational Stylistics. } \\
\text { Intermodal Translation. Systemic } \\
\text { Functional Linguistics. Grammar of } \\
\text { Visual Design. Colour Studies. }\end{array}$ \\
\hline
\end{tabular}

\section{Introdução}

O presente artigo tem por objetivo analisar um excerto da história em quadrinhos Ms. Marvel, Volume 1: No normal (2014), escrita por G. Willow Wilson com a arte de Adrian Alphona, e duas de suas traduções para o português, sendo uma para o português brasileiro e outra para o português europeu, sob o enfoque da Estilística Tradutória, da Tradução Intermodal, da Linguística Sistêmico-Funcional e da Gramática do Design Visual, utilizando, também, da noção de Termos Básicos de Cores. 
Aparentemente, a investigação da tradução interlinguística juntamente com a investigação da Tradução Intermodal, sob o viés da metafunção interpessoal, não é algo recorrente em pesquisas sobre histórias em quadrinhos. Ao examinarmos ambos os tipos de tradução do tipo de texto supracitado e da metafunção adotada, esperamos contribuir para preencher um nicho não muito explorado.

Investigamos a história em quadrinhos e suas traduções com base em categorias para as traduções interlinguísticas e categorias para as traduções intermodais. No tocante à tradução interlinguística, citamos a Estilística Tradutória (MALMKJAER, 2003, 2004) para pesquisar linguisticamente textos literários bem como textos criativos em relação de tradução; e a Linguística Sistêmico-Funcional (HALLIDAY; MATTHIESSEN, 2014) para o estudo da construção do significado no texto. Para fins de análise da Tradução Intermodal, utilizamos a Gramática do Design Visual, a qual nos apresenta como o modo semiótico verbal e o não-verbal são realizados (KRESS; van LEEUWEN, 2006). Além disso, em relação ao uso de cores, usamos o conceito de Termos Básicos de Cores (BERLIN; KAY, 1991).

O artigo justifica-se por apresentar uma análise ainda pouco explorada, a das histórias em quadrinhos sob o viés da Linguística Sistêmico-Funcional e da Gramática do Design Visual. Justifica-se também por utilizar a Estilística Tradutória de forma mais abrangente, analisando um outro tipo de texto criativo além do texto literário. Além disso, o artigo apresenta uma possibilidade de complementação da análise do modo semiótico visual utilizando o conceito de Termos Básicos de Cores.

Algumas perguntas guiaram o andamento da pesquisa, tais quais: como se realiza a tradução interlinguística, principalmente no que diz respeito à metafunção interpessoal? Como a metafunção interpessoal é realizada no modo semiótico visual? Como os modos semióticos verbal e visual interagem do ponto de vista da metafunção interpessoal? E como a utilização de cores, no modo semiótico visual, auxilia na construção do significado do texto? 
Para responder tais questões, selecionamos um excerto da história em quadrinhos, baseando-nos no conceito de "fase discursiva” (MARTIN; ROSE, 2007). Procuramos entender como a metafunção interpessoal é realizada tanto no campo verbal quanto no campo visual e como os dois modos semióticos se relacionam para a criação de significado do texto, levando em conta, também, o uso de cores.

O artigo, primeiramente, apresenta o referencial teórico, procurando explicitar as teorias e conceitos que foram utilizados para análise, como, por exemplo, a Linguística Sistêmico-Funcional e a Gramática do Design Visual. Após, apresentamos a metodologia, na qual explicamos como escolhemos o excerto a ser analisado, os procedimentos de análise e como foi feita a quantificação dos dados recolhidos, através do uso de planilhas eletrônicas. A seção seguinte enfocará a análise das obras, seguida das considerações finais que serão apresentadas tendo como base os resultados obtidos.

\section{Fundamentação teórica}

\subsection{Estilística Tradutória}

Malmkjaer $(2003,2004)$ preocupa-se com a semântica de textos-fonte literários e seus respectivos textos-alvo, preocupação esta que levou à criação do termo "Estilística Tradutória".

Uma análise estilística de um texto levaria em consideração como o texto possui determinado significado e o porquê das escolhas criativas feitas pela autora (MALMKJAER, 2003). Na visão de Malmkjaer (2003), essas escolhas são limitadas pelas convenções de gênero, por exemplo, ou por fatores linguísticos, políticos e ideológicos.

No que tange à Estilística Tradutória, as limitações que se apresentam à tradutora são ainda mais amplas, uma vez que ela tem de levar o texto-fonte em consideração (MALMKJAER, 2003). Segundo a autora, baseando-se no texto-fonte, a 
Estilística Tradutória visa à explicação do porquê de um texto traduzido possuir o significado que possui. Para tal, outros traços extralinguísticos, como as normas preliminares de tradução, postuladas por Toury (1995), por exemplo, devem ser considerados (MALMKJAER, 2003).

Para Malmkjaer (2004), a mediação através da tradução perpassa duas línguas e não haverá sempre correspondência entre muitos de seus aspectos (extra)linguísticos. Isso faz com que a tradutora tenha que fazer opções e encarar restrições (MALMKJAER, 2004). Para a autora, um texto literário mediado pela tradução possui quatro características que lhe são inerentes: 1) o texto é influenciado pelas opções e interpretações da mediadora; 2) a mediação através da tradução possui um objetivo; 3) a mediação e as opções da mediadora podem levar à criação de um texto cujo objetivo é distinto do objetivo do texto-fonte; e 4) o público-alvo do textofonte diferencia-se do público-alvo do texto mediado (MALMKJAER, 2004).

Assim, a Estilística Tradutória se preocupa com o entendimento dos significados que os textos-fonte literários e seus respectivos textos-alvo carregam. Por acreditarmos que um texto literário pode ser chamado de texto criativo, também acreditamos que a Estilística Tradutória possa ser utilizada para investigar outros textos criativos, como, no caso do presente artigo, as histórias em quadrinhos. E por acreditarmos também que esse entendimento semântico proposto pela Estilística Tradutória se coaduna com os princípios da Linguística Sistêmico-Funcional, introduzimo-la na próxima subseção.

\subsection{Linguística Sistêmico-Funcional}

A linguagem, para Halliday e Matthiessen (2014), está em constante evolução e é intrinsecamente verbal. Parte-se do pressuposto de que o texto é uma unidade semântica que pode ser visto per se ou como um meio para descobrir algo a mais (cf. HALLIDAY; MATTHIESSEN, 2014). A Gramática Sistêmico-Funcional, para os 
autores, pode ser considerada como uma série de sistemas, os quais são empregados pelas usuárias da língua ${ }^{1}$ para poder produzir significado.

A Linguística Sistêmico-Funcional apresenta três metafunções que podem ser simultaneamente referidas através da escala de ordens $^{2}$ (HALLIDAY; MATTHIESSEN, 2014). Metafuncionalmente, os significados podem ser construídos de forma interpessoal, ideacional e textual (THOMPSON, 2014). A metafunção interpessoal se refere ao uso da língua para comunicação com outra falante; a ideacional se relaciona a como representamos o mundo interno e externo no nível experiencial e no nível lógico-semântico; e a textual organiza as manifestações interpessoais e ideacionais em um contexto específico (THOMPSON, 2014). O presente trabalho lidará, como mencionado anteriormente, com a metafunção interpessoal.

O Modo Oracional (Mood) é a adaptação de partes da mensagem de uma falante por outra falante para que a comunicação possa seguir seu rumo, sendo que o cerne da resposta consiste em dois elementos, o Sujeito e o Finito; e, por conseguinte, a parte remanescente da oração é designada como Resíduo (THOMPSON, 2014). Para Thompson (2014), um dos propósitos fundamentais da linguagem é a de fornecer ou demandar uma mercadoria ${ }^{3}$ específica. No caso de a mercadoria ser informação, a linguagem possui uma função constitutiva, fazendo todo, ou quase todo, o trabalho de

\footnotetext{
${ }^{1}$ Em "Pode o subalterno falar?", Gayatri Spivak (2010) discorre sobre a construção do Outro a partir de uma visão eurocêntrica da realidade. Para a autora, o Outro criado pelo imperialismo europeu se vê sem um lugar de fala, sendo ensinado uma visão colonial da história. Sendo assim, para Spivak (2010), é necessário a construção de uma ambiente em que a voz da subalterna possa ser ouvida. Nesse sistema de supressão da voz da subalterna, o feminino "está ainda mais profundamente na obscuridade" (SPIVAK, 2010, p. 87), sendo o sujeito masculino colocado na posição de maior poder. Acreditamos, assim, que o uso do masculino genérico para denominar seres humanos como um todo somente coloca o feminino em uma situação de ainda menos poder e de maior subjugação. Por isso, escolhemos utilizar o feminino como pronome genérico para, assim, apresentar uma posição alternativa à dominação masculina e, seguindo o raciocínio de Spivak, dar voz ao Outro subordinado.

2 Tradução de rank scale proposta por Figueredo (2011).

${ }^{3}$ Tradução de commodity proposta por Figueredo (2011).
} 
comunicação (THOMPSON, 2014). Já no caso de bens e serviços, a linguagem possui uma função ancilar, auxiliando na comunicação (THOMPSON, 2014).

Assim, temos quatro principais papéis de fala: fornecer informações (declaração), demandar informações (pergunta), fornecer bens e serviços (oferta) e demandar bens e serviços (comando) (THOMPSON, 2014).

Segundo o autor, três dessas funções podem ser associadas com funções gramaticais específicas: declarações são expressas por orações declarativas; perguntas são expressas por orações interrogativas; e comandos são expressos por orações imperativas.

O termo "modalidade" se refere à credibilidade de uma sentença, sendo que alguns dos marcadores de modalidade podem ser verbos auxiliares, como may e must, e adjetivos, como possible e probable (HALLIDAY, 1985 apud KRESS; van LEEUWEN, 2006). A modalidade, segundo Thompson (2014), pode ser vista como a construção de uma "aura" interpessoal da atitude da falante sobre o que está sendo falado. Há dois tipos de modalidade: modalização e modulação (THOMPSON, 2014). A modalidade pode ser investigada a partir do comprometimento da falante com o que está sendo dito ou se a falante assume responsabilidade pelo que está sendo dito - o que pode acontecer de forma subjetiva ou objetiva e implícita ou explícita (THOMPSON, 2014).

A seguir mostramos um trabalho sobre um traço da metafunção interpessoal em histórias em quadrinhos no par de línguas português/inglês.

Pagano, Sá e Ferreguetti (2014) analisam a equivalência tradutória das Partículas Modais em histórias em quadrinhos da Turma da Mônica traduzidas do português para o inglês. As autoras e o autor procuram verificar quais as Partículas mais utilizadas e como tais Partículas foram traduzidas para o inglês. Além disso, procuram entender como o significado das Partículas em português é realizado em inglês e o que pode ser averiguado acerca do funcionamento das Partículas com base na análise. Para tal, as autoras e o autor lançam mão da metafunção interpessoal de 
Halliday e Matthiessen (2004). O corpus das autoras e do autor contou com onze histórias da Turma da Mônica, de Maurício de Souza, e suas traduções para a língua inglesa. Foram encontradas 93 ocorrências de Partículas Modais no corpus, sendo elas Anuência, Confirmação, Exclamação, Conclusão, Atenuação, Atenção, Concordância e Exortação; no corpus traduzido, algumas Partículas, como as de Anuência, foram traduzidas como tag questions (PAGANO; SÁ; FERREGUETTI, 2014). As autoras e o autor concluem que os padrões de utilização das Partículas Modais em português brasileiro são traduzidos para elementos específicos de língua inglesa, sendo que em língua inglesa, diferentemente da língua portuguesa, não são utilizados somente itens lexicais, mas também recursos gramaticais e prosódicos.

\subsection{Interatividade entre a linguagem visual e verbal}

Doloughan (2011) explora como imagens podem ser utilizadas tanto por si mesmas quanto em conjunto com o intuito de formar uma narrativa, examinando como as escritoras utilizam-se dos recursos visuais e verbais para narrar suas histórias, recursos esses que podem realizar traduções intermodais quando se encontram em interação. A autora enfatiza a análise de "como texto e imagem interagem e os efeitos de tal interação em termos da produção e recepção do significado" ${ }^{4}$ (DOLOUGHAN, 2011, p. 24).

Kress (2003 apud DOLOUGHAN, 2011) argumenta que as práticas literárias que temos por costumeiras estão se modificando, se direcionando para uma prática mais multimodal. Segundo ele, o modo visual e o modo verbal se diferem na apresentação, pois a linguagem verbal é mais esquemática do que a visual.

Para Kress e van Leeuwen (2006 apud DOLOUGHAN, 2011), a linguagem visual apresenta sua própria estrutura. Por exemplo, conforme os autores (apud

\footnotetext{
${ }^{4}$ No original: "(...) how text and image interact and on the effects of such interaction in terms of the production and reception of meaning."
} 
DOLOUGHAN, 2011), princípios do design e da composição podem ser utilizados por escritoras para a criação de significado. Tanto o que é excluso como incluso em uma composição apresentam significado (KRESS; van LEEUWEN, 2006 apud DOLOUGHAN, 2011).

Tal pensamento é compartilhado por Diniz (1999), a qual menciona que cada atividade semiótica produzirá seu sistema de significados. Segundo ela, essas atividades semióticas não são apenas linguagens "em seu meio de expressão, mas constituem procedimentos que permitem especificar seus processos e práticas semióticas distintas" (DINIZ, 1999, p. 31). Para a autora, é necessário enfatizar que cada sistema possui aspectos próprios que moldam a equivalência durante a tradução e que levam a uma determinada experiência por parte da espectadora.

Consoante Karatza (2017), os diferentes modos semióticos trabalham conjuntamente para a construção do significado em potencial de um determinado texto. As imagens auxiliam na demonstração daquilo que levaria muito tempo para descrever, enquanto a linguagem escrita representa aquilo que é difícil de ser enquadrado em imagens (KRESS, 2010 apud KARATZA, 2017). Os diferentes modos semióticos apresentam, também, lógicas diferentes: a lógica do tempo governa o texto escrito e a lógica da espacialidade e simultaneidade governa a imagem (KRESS, 2003 apud KARATZA, 2017). O significado de um texto é construído por meio da contribuição de todos os modos, concomitantemente, pois cada modo contribui de uma maneira particular para a criação do significado em um texto multimodal (KRESS, 2010 apud KARATZA, 2017).

\subsection{Gramática do Design Visual}

Os modos semióticos visual e verbal, conforme Kress e van Leeuwen (2006), possuem formas específicas de realização. O que é expresso na linguagem mediante verbos de ação, pode ser expresso por vetores no modo visual (KRESS; van 
LEEUWEN, 2006). No entanto, nem todas as relações feitas de forma verbal podem ser expressas de forma visual, sendo a recíproca verdadeira (KRESS; van LEEUWEN, 2006). Os modos semióticos apresentam suas próprias potencialidades e limitações, sendo, também, determinados social e historicamente (KRESS; van LEEUWEN, 2006).

Para os autores, pouco se estudou sobre a estruturação visual e, em sua opinião, esta vem sendo tratada apenas como um espelho da realidade. Kress e van Leeuwen (2006) acreditam que as imagens da realidade estão atreladas a interesses de instituições sociais, as quais produzem e divulgam as imagens. Por consequência, as estruturas visuais apresentam um cunho ideológico e detêm uma dimensão semântica relevante (KRESS; van LEEUWEN, 2006). Baseando-se nessas reflexões foi criada a Gramática do Design Visual.

Todas as escolhas imagéticas carregam significado. As formas geométricas, por exemplo, apresentam um significado que não é intrínseco a elas, mas que é produzido pela sociedade e cultura das quais advêm. A reunião dos elementos em um todo coerente é o que possibilita o entendimento dos textos visuais (KRESS; van LEEUWEN, 2006).

As imagens podem ser analisadas de acordo com a direção do olhar. Para Kress e van Leeuwen (2006), há uma diferença entre imagens que mostram as Participantes Representadas olhando diretamente nos olhos da visualizadora e aquelas que não o fazem. Usando os conceitos de Halliday (1985 apud KRESS; van LEEUWEN, 2006), o tipo de imagem em que há contato visual pode ser chamada de "demanda", pois demanda algo das visualizadoras, um tipo de relação imaginária (KRESS; van LEEUWEN, 2006). Já o tipo de imagem em que não há contato visual entre a Participante Representada e a visualizadora são chamadas de "oferta" pois fornecem informações para quem as visualiza (KRESS; van LEEUWEN, 2006).

Como membros da sociedade, precisamos decidir se confiamos ou não em algo, se algo é verdadeiro ou não; assim, podemos nos basear nos marcadores de 
modalidade que são apresentados na mensagem (KRESS; van LEEUWEN, 2006). Segundo os autores, os marcadores de modalidade são construídos pelo grupo social com o qual nós interagimos e servem como guias para a confiabilidade das mensagens, sendo desenvolvidos com base nos valores, crenças e necessidades do grupo. Os autores postulam que existem "pistas de modalidade", signos motivados, ou seja, aqueles que nascem do interesse de grupos sociais, os quais interagem com outros grupos sociais dentro de uma sociedade.

A modalidade, para Kress e van Leeuwen (2006), pode ser interpessoal, pois não expressa verdade ou mentira, mas sim produz verdades ou mentiras que estejam alinhadas com as expectativas das consumidoras da linguagem.

Quando se trata do visual, o conceito de modalidade também é essencial (KRESS; van LEEUWEN, 2006). Kress e van Leeuwen (2006) determinam que as imagens também são criações sociais e a modalidade destas depende do que é considerado real por um certo grupo social.

De acordo com os autores, o uso de cores é importante para que possamos julgar a modalidade de uma imagem. Kress e van Leeuwen (2006) afirmam que o quanto mais abstraídas são as cores, quanto mais reduzidas, menor é a modalidade.

Assim, os autores apresentam alguns marcadores de modalidade: 1) a saturação das cores; 2) a diferenciação de cores; 3) a modulação das cores; 4) a contextualização (no que se refere ao plano de fundo das imagens, se são detalhados ou não); 5) a representação (abstração ou representação de detalhes pictóricos); 6) a profundidade; 7) a iluminação; e 8) o brilho.

Outro detalhe importante é o de codificação de orientação, ou seja, princípios abstratos que nos informam quais grupos sociais ou instituições produziram as mensagens. Algumas codificações de orientação são: 1) tecnológicas; 2) sensoriais; 3) abstratas; e 4) naturalistas (KRESS; van LEEUWEN, 2006). 
Moya Guijarro, em seu livro sobre análise multimodal de livros infantis ilustrados, analisa o livro Where the wild things are (SENDAK, 2007) levando em consideração quatro elementos para verificar como a metafunção interpessoal se manifesta na história: 1) atos imagéticos e olhar; 2) interação social: distância e intimidade; 3) ângulo horizontal; e 4) ângulo vertical (MOYA GUIJARRO, 2014 cf. KRESS; van LEEUWEN, 1996, 2006). O autor conclui que há uma predominância (96\%) de ofertas quando se trata do olhar e do ato imagético, o que apresenta informações sobre a criança protagonista à leitora. No caso da interação social, o plano médio é o mais presente $(72 \%)$, o que mostra o envolvimento entre a personagem principal e as outras Participantes Representadas (MOYA GUIJARRO, 2014). O ângulo horizontal está associado com envolvimento, sendo que 96\% dos ângulos analisados são oblíquos, com exceção de duas páginas duplas com ângulo frontal, o que cria uma interação entre a leitora e a personagem principal (MOYA GUIJARRO, 2014). Por último, o ângulo vertical está associado a poder, sendo que, no livro, todas as imagens estão no nível do olhar, levando a entender que a leitora está no mesmo patamar da personagem principal (MOYA GUIJARRO, 2014).

\subsection{Estudos das Cores}

Berlin e Kay (1991) apresentam o conceito de Termos Básicos de Cores, o qual indica que diferentes línguas possuem em seu vocabulário um conjunto de Termos Básicos de Cores, como "branco", "vermelho", "amarelo", "verde", "azul", "preto", "cinza", "laranja", "marrom", "rosa" e "roxo". Com base nos estudos de Berlin e Kay, vários outros foram surgindo, indo desde a análise linguística até a análise de uma possível significação das cores.

De acordo com Biggam (2015), as cores performam vários papéis em nossas vidas: elas são uma constante em nosso dia a dia, podendo representar conexões a países ou instituições ou passar informações vitais para nossa segurança, como no caso 
de semáforos. Biggam (2015) afirma que os Termos Básicos de Cores podem representar metáforas corriqueiras de linguagem, como a expressão inglesa to feel blue, que representa tristeza.

No entanto, como apresentado por van Leeuwen (2011), esses significados não são naturais às falantes de uma língua: eles são impostos através de explicações autoritativas e discursos normativos que se naturalizam em uma sociedade. Isso vai ao encontro do que é dito por Sutrop (2011). Consoante Sutrop (2011), as cores são o alfabeto da linguagem visual. Segundo o autor, as cores devem ser analisadas sempre dentro de um contexto. Para ele, muitos dos problemas enfrentados por pesquisadoras ao estudar os Termos Básicos de Cores advêm da retirada das cores de seu contexto de significação. Assim, uma teoria semiótica dos Termos Básicos de Cores deveria "colocar os termos de cores novamente em um contexto linguístico, histórico e cultural" $^{5}$ (SUTROP, 2011, p. 43).

As cores também podem realizar a metafunção interpessoal, pois auxiliam na comunicação, representando ideias, valores e significados (van LEEUWEN, 2011).

Conforme van Leeuwen (2011), uma análise do significado das cores deve levar em consideração três categorias: todos os aspectos de uma cor devem ser considerados; as características materiais da cor devem ser analisadas, assim como o potencial de significado que carregam; e, por último, o potencial de significado dos "esquemas de cores" também deve ser levado em conta, não somente o potencial de significado das cores isoladas.

O autor trata da utilização das cores em jornais e revistas, mencionando que, neste tipo de publicação, "a conexão entre as palavras agora é visual"6 (van LEEUWEN, 2011, p. 92, grifo do autor), pois o que dá sentido ao texto escrito é o leiaute, as cores e

\footnotetext{
${ }^{5}$ No original: "place the colour terms back into a linguistic, historical and cultural context."

${ }^{6}$ No original: "the connection between the words is now visual."
} 
a tipografia. Esse tipo de publicação "mistura o visual e o verbal de novas maneiras"7 (van LEEUWEN, 2011, p. 93) o que, acreditamos, também possa ser dito das histórias em quadrinhos.

\section{Metodologia}

\subsection{Os quadrinhos escolhidos}

Os quadrinhos da Ms. Marvel, com Kamala Khan de protagonista, vêm sendo publicados desde 2013 pela Marvel Comics. Para os propósitos desta análise escolhemos o primeiro volume da série, intitulado Ms. Marvel, Volume 1: No normal (2014), e suas traduções para o português brasileiro e o português europeu. A tradução para o português brasileiro foi feita por Rodrigo Barros e Paulo França e publicada pela Panini Comics em 2015, enquanto a tradução para o português europeu foi feita por Bernardo Rodrigues e publicada pela G. FLOY STUDIO em 2018. O volume em questão é escrito por G. Willow Wilson com a arte de Adrian Alphona.

Os quadrinhos narram a história da adolescente estadunidense, de origem paquistanesa, Kamala Khan. Uma noite, Kamala vai até uma festa e é surpreendida pela névoa terrígena, a qual desperta seus poderes inumanos. A partir desse momento, a personagem precisa aprender a controlar os seus poderes e a virar a super-heroína que sempre desejava ser, tomando o manto de Ms. Marvel.

O trecho escolhido narra a transformação de Kamala em uma inumana e o teste de seus poderes, o que, mais tarde, a levará a se tornar a Ms. Marvel. O trecho foi escolhido por ser uma fase discursiva de grande significância, pois narra os eventos que dão início ao resto dos acontecimentos. Segundo Martin e Rose (2007), a fase discursiva determina a progressão lógica dos eventos de uma narrativa. Cumpre

\footnotetext{
${ }^{7}$ No original: "mixes the visual and the verbal in new ways."
} 
observar que um balão, o qual estava em urdu, foi desconsiderado da passagem selecionada.

\subsection{Procedimentos de análise}

Para a realização da análise foram selecionadas categorias para as traduções interlinguísticas e categorias para as imagens.

Para as categorias de traduções interlinguísticas, foram levados em conta o papel na troca e a mercadoria trocada, ou seja, o Fornecimento ou a Demanda de Informações ou de Bens e Serviços; e a Modalidade: a Modalização e a Modulação. Essas categorias, consoante Halliday e Matthiessen (2014), estão relacionadas com a metafunção interpessoal.

As categorias para as imagens basearam-se no contato visual, o qual demonstra Oferta e/ou Demanda (KRESS; van LEEUWEN, 2006); e nas cores, através da identificação dos Termos Básicos de Cores (BERLIN; KAY, 1991). Como nos painéis analisados não há nenhuma instância de contato visual direto com a leitora, consideramos contato visual os momentos em que os olhos das personagens estão na linha de visão direta de quem está visualizando a imagem. No que tange às cores, somente foram consideradas as cores que se encaixavam nos Termos Básicos de Cores, sendo que as outras cores foram desconsideradas. E, posteriormente, identificaram-se quais Termos Básicos de Cores foram mais recorrentes.

Os dados foram compilados em uma planilha XSL. Esta apresenta cinco abas, as quais estão divididas em: Ms. Marvel texto-fonte (TF), em inglês; Ms. Marvel textoalvo 1 (TA1), em português brasileiro; Ms. Marvel texto-alvo 2 (TA2), em português europeu; Ms. Marvel Aspectos Visuais 1; e Ms. Marvel Aspectos Visuais 2. Nas três primeiras abas, foram colocados, na primeira coluna, o número de cada balão de fala ou legenda analisados. Na primeira linha, a aba foi separada em Fornecimento, Demanda, Informação, Bens e Serviços, Modalização e Modulação, sendo que, para 
cada uma dessas categorias, foi sinalizado SIM ou NÃO quando estas se realizaram ou não no balão ou legenda correspondentes. Na aba Ms. Marvel Aspectos Visuais 1, na primeira linha foram colocadas as categorias Oferta, Demanda e Termos Básicos de Cores, sendo, novamente, indicado SIM ou NÃO para a realização ou não de tais categorias nos referentes painéis. Já na aba Ms. Marvel Aspectos Visuais 2 foi apresentado o Termo Básico de Cor predominante nos painéis que receberam SIM conforme a classificação na aba Ms. Marvel Aspectos Visuais 1. Além disso, utilizou-se a função CONT.SE para quantificar os campos que apresentaram SIM nas quatro primeiras abas. No tocante aos Termos Básicos de Cores, na quinta aba, a quantificação foi feita manualmente. Após a quantificação dos dados, foram geradas tabelas com os resultados apresentados, as quais foram descritas, analisadas e relacionadas.

A título de exemplificação, utilizou-se a função CONT.SE para quantificar as ocorrências de SIM na aba Ms. Marvel texto-fonte no que tange à categoria Fornecimento. Para tal, utilizou-se a fórmula Plan1!B2:B63;"sim”, na qual "Plan1!B2:B63" refere-se à aba e à coluna selecionada, além dos números de linha, os quais se referem a cada balão ou legenda. Já "sim" refere-se ao dado a ser quantificado. No caso, foram encontradas 37 instâncias de Fornecimento no texto-fonte e nos textosalvo.

O uso de planilhas eletrônicas para investigações linguísticas apresenta várias vantagens, dentre elas a disponibilidade de tais planilhas em um grande número de computadores, sua versatilidade, a variada gama de funções disponíveis, a facilidade na sistematização de dados e sua portabilidade (ALVES, 2014 apud ALVES; ASSIS, 2016).

\section{Resultados e discussão}

Esta seção traz os resultados obtidos tendo como base a fundamentação teórica empregada e a metodologia adotada. Cabe informar que o TF se refere ao texto-fonte 
em inglês; o TA1 corresponde ao texto-alvo em português brasileiro e, por fim, o TA2 diz respeito ao texto-alvo em português europeu.

Observemos a Tabela 1.

Tabela 1- Dados interlinguísticos das abas de Ms. Marvel Volume, 1: No normal, Tradução para o Português Brasileiro e Tradução para o Português Europeu.

\begin{tabular}{c|c|c|c}
\hline & TF & TA1 & TA2 \\
\hline Fornecimento & 37 & 37 & 37 \\
\hline Demanda & 15 & 15 & 15 \\
\hline Informação & 42 & 42 & 42 \\
\hline Bens e Serviços & 11 & 11 & 11 \\
\hline Modalização & 10 & 10 & 10 \\
\hline Modulação & 7 & 7 & 7
\end{tabular}

Na Tabela 1 pode-se ver a quantificação dos dados interlinguísticos das primeiras três abas criadas na planilha eletrônica. Tais abas correspondem ao textofonte (TF), à tradução para o português brasileiro (TA1) e à tradução para o português europeu (TA2). Segundo a quantificação dos dados, foram obtidas 37 ocorrências de Fornecimento; 15 ocorrências de Demanda; 42 de Informação; 11 de Bens e Serviços; 10 de Modalização; e 7 de Modulação. Os dados são idênticos para os três textos analisados. Isso significa que não há variação nos papéis de fala (HALLIDAY; MATTHIESSEN, 2014; THOMPSON, 2014), ou seja, no Fornecimento e na Demanda; e nem nas mercadorias trocadas (cf. HALLIDAY; MATTHIESSEN, 2014; THOMPSON, 2014), a saber, na Informação e nos Bens e Serviços. Desse modo, observa-se que a interação no TA1 e no TA2, em cotejo com o TF, não se modifica em termos do sistema semântico de função de fala (HALLIDAY; MATTHIESSEN, 2014). Tal fato pode demonstrar que os textos traduzidos estão sob esse aspecto em sintonia com o TF, uma história em quadrinhos, e que não promovem mudanças de tradução sob essa perspectiva justamente porque talvez desejem que o traço interativo seja semelhante ao $\mathrm{TF}$, o que pode relacionar-se a questões de mercado editorial. Tais questões, 
conforme Malmkjaer (2003), poderiam explicar o porquê desse padrão de escolhas sob o ponto de vista aqui investigado. Observa-se também que o Fornecimento é mais abundante que a Demanda, indicando que, sob essa perspectiva, as ofertas e as declarações possam ser priorizadas em detrimento dos comandos e das perguntas no TF e nos TA1 e TA2. Verifica-se, contudo, que os excertos analisados apresentam, de acordo com Halliday e Matthiessen (2014), mais proposições que propostas, pois há mais ocorrências de Informação que de Bens e Serviços. Assim, são feitas, sob esse viés, mais declarações e perguntas que ofertas e comandos nos textos em análise. No que tange à Modalidade (HALLIDAY; MATTHIESSEN, 2014), a Modalização e a Modulação se manifestam poucas vezes, mostrando que a autora e os tradutores não optam, com frequência, por realizações no contínuo entre o "sim" categórico e o "não" categórico, se considerados os excertos em questão.

A seguir, serão apresentados exemplos de cada uma das categorias da tradução interlinguística. Primeiramente, serão apresentados exemplos de Fornecimento de Informação, retirados da Legenda de número 1.

\begin{tabular}{|c|c|c|}
\hline \multicolumn{2}{|c|}{ Quadro 1 - Exemplos de Fornecimento nos três textos analisados. } \\
\hline TF & TA1 & TA2 \\
\hline $\begin{array}{c}\text { "I should have known } \\
\text { better." }\end{array}$ & "Eu já devia saber." & $\begin{array}{c}\text { "Já devia ter } \\
\text { adivinhado." }\end{array}$ \\
\hline
\end{tabular}

Fonte: elaborado pelas autoras.

Pode-se ver, no Quadro 1, que as orações expressam Fornecimentos de Informação (HALLIDAY; MATTHIESSEN, 2014), pois são declarações. Kamala, ao voltar de uma festa clandestina, começa a pensar no fato de não se encaixar com as outras pessoas de sua idade. Nesse momento, ela pensa que já deveria ter imaginado que as coisas não sairiam do jeito que ela imaginava. Além de apresentar Fornecimentos de Informação, as orações também apresentam Modulações 
(THOMPSON, 2014) em função do Finito modal should, em inglês, e "devia" em português que indicam Inclinação.

Um exemplo de Demanda de Informação encontra-se na Legenda de número 2:

Quadro 2 - Exemplos de Demanda de Informação nos três textos analisados

\begin{tabular}{|c|c|c|}
\hline TF & TA1 & TA2 \\
\hline “Who was I kidding?" & $\begin{array}{c}\text { "Quem eu queria } \\
\text { enganar?" }\end{array}$ & $\begin{array}{c}\text { "No que estava a } \\
\text { pensar?" }\end{array}$ \\
\hline
\end{tabular}

Fonte: elaborado pelas autoras.

A Legenda 2 dá prosseguimento a um pensamento de Kamala no que tange a suas ideias de possível pertencimento a seu grupo social. Assim, conforme Thompson (2014), as três orações interrogativas demandam uma informação que não exige uma resposta com polaridade de "sim" ou "não".

Pode-se observar no Quadro 2 que as diferenças nas traduções se relacionam a como o português brasileiro e o português europeu apresentam suas peculiaridades ao usar a língua. Além disso, pode-se afirmar que a tradução para o português brasileiro é mais literal ao passo que a tradução para o português europeu parece apresentar uma mudança de tradução.

Como exemplo de Demanda de Bens e Serviços podemos apresentar a Legenda 4:

Quadro 3 - Exemplos de Demanda de Bens e Serviços nos três textos analisados.

\begin{tabular}{|c|c|c|}
\hline TF & TA1 & TA2 \\
\hline "Wait." & "Peraí." & "Espera." \\
\hline
\end{tabular}

Fonte: elaborado pelas autoras.

Kamala começa a sentir-se tonta, repentinamente. Assim, profere uma oração imperativa, o que demonstra uma Demanda de Bens e Serviços (HALLIDAY; MATTHIESSEN, 2014). Ademais, a tradução para o português brasileiro emprega um modo coloquial do verbo "esperar", o que não ocorre com a tradução para o português 
europeu, apesar de esta fazer o comando tendo o pronome pessoal "tu" em mente. O uso de "tu" nesse contexto pode ser considerado mais informal.

Mostramos um exemplo de Fornecimento de Bens e Serviços na Legenda 5.

Quadro 4 - Exemplos de Fornecimento de Bens e Serviços nos três textos analisados.

\begin{tabular}{c|c|c}
\hline TF & TA1 & TA2 \\
\hline "Can you get drunk & "Dá pra ficar bêbada & "Podemos ficar bêbados \\
from one sip of & com um gole de alguma & só com um gole? Que \\
something? That you & coisa? Que você cuspiu & cuspimos logo?" \\
immediately spit out?" & na hora?" & \\
\hline
\end{tabular}

Fonte: elaborado pelas autoras.

Por se tratar de perguntas, proferidas por Kamala Khan, cujas respostas podem ser "sim" ou "não", as orações são consideradas exemplos de Fornecimento de Bens e Serviços. Além do mais, elas apresentam Modalizações que podem ser verificadas através do Finito modal can e seus correspondentes em português. Podemos perceber uma forma alternativa de indicar possibilidade na oração em português brasileiro. Nessa oração can foi traduzido por "dá pra" ao passo que na oração em português europeu a tradução apresenta mais literalidade. Ademais, a tradução de can para o português brasileiro pode ser vista como mais impessoal em comparação ao TF e ao TA em português europeu.

Pagano, Sá e Ferreguetti (2014) investigam as Partículas Modais nas histórias em quadrinhos Turma da Mônica e em suas traduções para o inglês, observando as diferenças manifestas dessa categoria entre ambas as línguas. A categoria utilizada pelas autoras e pelo autor é microtextual. No excerto em análise de Ms. Marvel Volume 1: No normal e suas respectivas traduções para o português, vemos que microtextualmente o TF e os TA1 e TA2 se diferem quanto a algumas realizações interpessoais, porém em nível de sistema semântico de função de fala, conforme apontado por Halliday e Matthiessen (2014), os excertos são idênticos. Uma outra possível explicação para essa similaridade pode ser encontrada no meio em que se está 
sendo traduzido, o de quadrinhos de super-heróis mainstream. Como pode ser observado, as orações não são muito longas por causa da restrição de espaço dos balões e das legendas, além de possibilitarem uma leitura rápida. Apesar disso, pode-se entender que, mesmo sendo mainstream, os TA1 e TA2 buscam atender a seus respectivos públicos-alvo, que notadamente são diferentes daquele do $\mathrm{TF}$, como aponta Malmkjaer (2004), em função das distintas escolhas microlinguísticas de caráter interpessoal observadas nas traduções.

Vejamos a Tabela 2.

Tabela 2 - Ms. Marvel Visual 1 - quantificação de Demanda e Oferta.

\begin{tabular}{c|c}
\hline & Ms. Marvel \\
\hline Oferta & 30 \\
\hline Demanda & 10 \\
\hline Fonte: elaborada pelas autoras.
\end{tabular}

Ao examinarmos a Tabela 2, podemos perceber que os painéis investigados no TF e nos TA1 e TA2 apresentam mais ocorrências de Oferta que de Demanda, categorias essas propostas por Kress e van Leeuwen (2006) com base em Halliday (1985). Isso alude ao fato de que, com frequência, as personagens nos painéis não travam um contato visual com a visualizadora, não estabelecendo, assim, nos termos de Kress e van Leeuwen (2006), uma relação imaginária, a qual comumente ocorre quando há Demanda, ou seja, quando há contato visual entre as personagens e a visualizadora. A recorrência de Oferta nas passagens selecionadas de Ms. Marvel, Volume 1 No normal e traduções está em consonância com a pesquisa de Moya Guijarro (2014) sobre o livro ilustrado infantil Where the wild things are (SENDRAK, 2007), em que a Oferta é também mais frequente que a Demanda nas imagens.

A despeito de o Fornecimento ocorrer em maior grau que a Demanda nas legendas e nos balões de fala, o que coaduna, em termos de Tradução Intermodal, com a frequência elevada de Oferta em comparação à Demanda nos painéis, mostramos, a 
seguir, dois exemplos de que a Oferta realizada no painel nem sempre significa que haja Fornecimento na legenda ou no balão de fala; e de que a Demanda presente no painel também não significa que exista a todo o momento Demanda na legenda ou no balão de fala.

O Quadro 2, já visto nesta seção, traz Demandas de Informação (HALLIDAY; MATTHIESSEN, 2014) em suas legendas relativas ao TF e aos TA1 e TA2 ao passo que no painel, comum a todos esses textos, há uma Oferta (KRESS; van LEEUWEN, 2006). No painel, Kamala encontra-se a caminho de casa, depois de sair de uma festa, pensando que não pertencia ao grupo, sendo tratada como "outro", e não estabelece um contato visual com a visualizadora.

Consideremos em seguida o Quadro 5.

Quadro 5 - painel 14 apresenta Demanda e balão de fala 14 apresenta Fornecimento de Informação.

\begin{tabular}{|c|c|c|}
\hline TF & TA1 & TA2 \\
\hline $\begin{array}{l}\text { "Zoe thought that } \\
\text { because I snuck out, it } \\
\text { was okay for her to make } \\
\text { fun of my family. Like, } \\
\text { Kamala's finally seen the } \\
\text { light and kicked the } \\
\text { dumb inferior brown } \\
\text { people and their rules to } \\
\text { the curb." }\end{array}$ & $\begin{array}{l}\text { "Zoe pensou que, por eu } \\
\text { ter fugido, não tinha } \\
\text { problema se zombasse } \\
\text { da minha família. Tipo, } \\
\text { Kamala finalmente } \\
\text { acordou e mandou o } \\
\text { povo moreno inferior } \\
\text { burro e suas regras pras } \\
\text { cucuias." }\end{array}$ & $\begin{array}{l}\text { "Como saí às escondidas, } \\
\text { a Zoe pensou que podia } \\
\text { gozar com a minha } \\
\text { família. Tipo, a Kamala } \\
\text { finalmente ganhou juízo } \\
\text { e mandou as pessoas } \\
\text { escuras e inferiores e as } \\
\text { suas regras parvas dar } \\
\text { uma curva." }\end{array}$ \\
\hline
\end{tabular}

Fonte: elaborado pelas autoras.

O Quadro 5 manifesta uma situação oposta ao exemplo anterior, isto é, nos painéis tem-se uma Demanda (KRESS; van LEEUWEN, 2006) e nos balões de fala temse um Fornecimento de Informação (THOMPSON, 2014). Nos painéis, Kamala explica para os Vingadores com os quais está alucinando que saiu escondida de casa para ir à festa, pensando que, assim, seria aceita por suas colegas. Mas, ao contrário, as colegas riram dela e de sua família, criticando sua cultura e religião. Como foi identificada uma Demanda nesses painéis, isso significa que Kamala estabelece um contato visual com 
a visualizadora. Nos balões de fala, há Fornecimento de Informação em função de as orações serem declarações. Além disso, pode-se considerar que ocorre uma Modalização por meio de uma metáfora interpessoal (HALLIDAY; MATTHIESSEN, 2014) indicada pelos verbos thought, "pensou" e "pensou", pois seu uso pode sinalizar uma possibilidade ou probabilidade do que está sendo comunicado via Resíduo das orações.

Verifiquemos a Tabela 3 em seguida.

Tabela 3 - Ms. Marvel Visual 1 - quantificação da utilização dos Termos Básicos de Cores.

\begin{tabular}{c|c}
\hline & Ms. Marvel \\
\hline Termos & \\
Básicos de & 37 \\
Cores & \\
\hline
\end{tabular}

Fonte: elaborada pelas autoras.

Os Termos Básicos de Cores foram identificados de acordo com a tipologia proposta por Berlin e Kay (1991). Como pode ser visto na Tabela 3, dos 40 painéis, 37 apresentam Termos Básicos de Cores. Consoante Kress e van Leeuwen (2006), as cores constituem indicativos de Modalidade em imagens. Desse modo, podemos constatar que a Modalidade é saliente nos painéis investigados do TF e dos TA1 e TA2, uma vez que parece não haver muitas abstrações de cor nesses painéis. Kress e van Leeuwen (2006) assinalam que a abstração e a redução de cores denotam uma diminuição da Modalidade em imagens.

Vejamos a Tabela 4 . 
Tabela 4: quantificação dos Termos Básicos de Cores predominantes.

\begin{tabular}{c|c}
\hline $\begin{array}{c}\text { Termos } \\
\text { Básicos de } \\
\text { Cores }\end{array}$ & Ms. Marvel \\
\hline Vermelho & 16 \\
\hline Amarelo & 14 \\
\hline Branco & 13 \\
\hline Cinza & 9 \\
\hline Preto & 2 \\
\hline Marrom & 1 \\
\hline Azul & 1 \\
\hline
\end{tabular}

Fonte: elaborada pelas autoras.

Dos 11 Termos Básicos de Cores elencados por Berlin e Kay (1991), os painéis investigados contemplam 7 Termos com destaque para o vermelho, o amarelo e o branco. Observando o contexto, conforme sugerido por Surtrop (2011), podemos perceber que os Termos Básicos de Cores mais recorrentes se referem à protagonista, Kamala Khan, cujo suéter apresenta as cores amarelo e branco; à Kamala Khan como Ms. Marvel, cujo traje de super-heroína possui a cor vermelha. Dessa forma, os Termos Básicos de Cores podem apresentar informações relevantes sobre as personagens de histórias em quadrinhos e podem indicar, de acordo com van Leeuwen (2011), o potencial de significado veiculado.

A seguir observemos a Figura 1. 

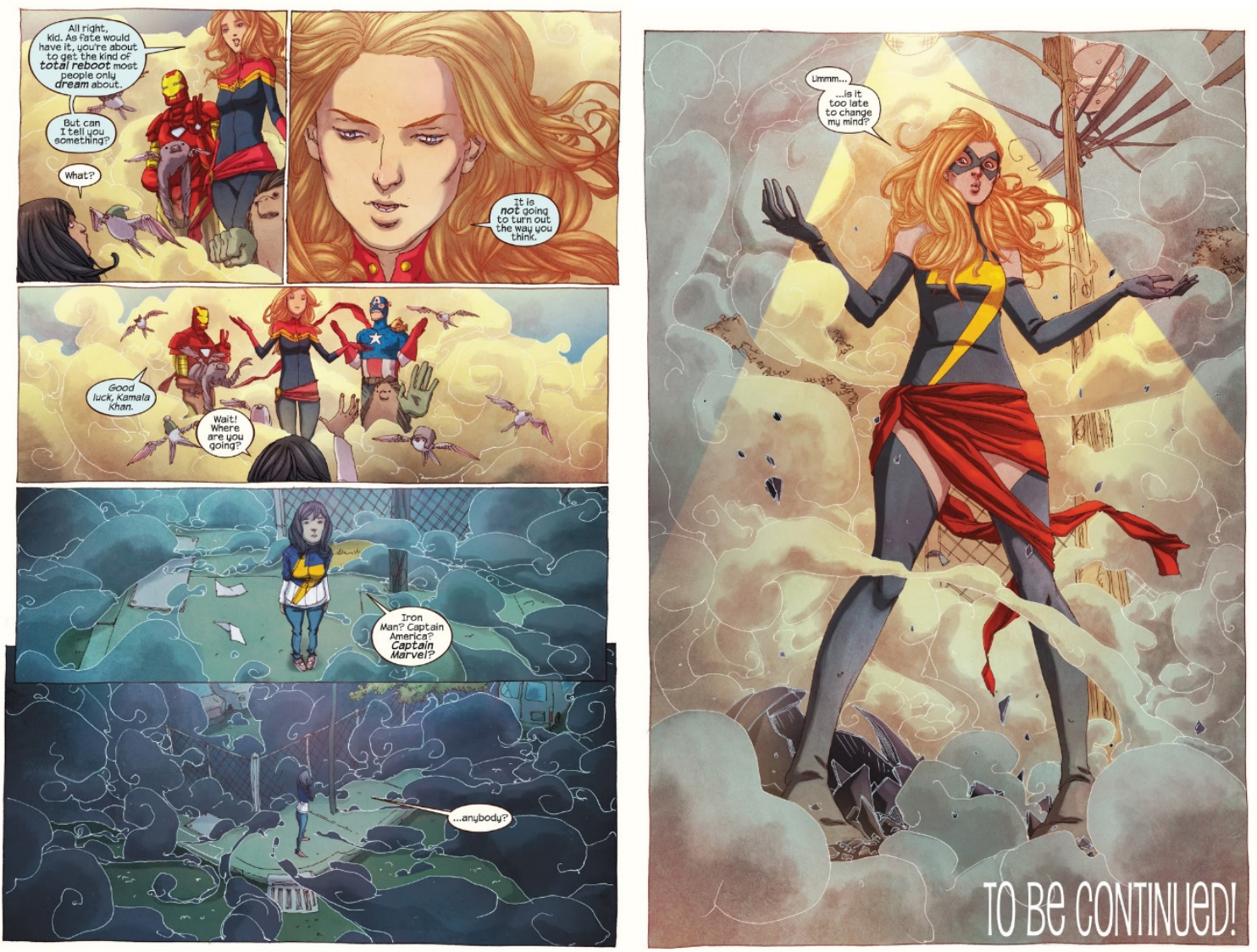

Figura 1: Kamala Khan e Ms. Marvel. (C) Marvel Comics. Todos os direitos reservados. FONTE: Wilson et al, 2014.

Como podemos ver na Figura 1, na imagem à esquerda, quarto painel, as cores em destaque na roupa de Kamala são o branco e o amarelo; enquanto na imagem à direita, painel único, as cores predominantes são o amarelo e o vermelho. Outras cores, como o azul-marinho do suéter de Kamala, não foram consideradas na análise por não constituírem um Termo Básico de Cor.

A partir da Figura 1, e de sua inclusão no todo, podemos fazer conjeturas sobre a personagem de Kamala e sua conexão com outras super-heroínas, especialmente a Capitã Marvel. Na imagem à direita, Kamala aparece utilizando-se da imagem da Capitã Marvel enquanto ainda era conhecida como Ms. Marvel, nome posteriormente utilizado por Kamala em sua carreira heroica. Como podemos ver, tanto o suéter de Kamala quanto a roupa de Ms. Marvel apresentam o amarelo como um Termo Básico de Cor predominante. Não somente isso, mas o amarelo está na forma de um raio em 
ambas as roupas, o que pode indicar a conexão de Kamala com a Capitã Marvel, sua heroína preferida.

Tendo como base a fundamentação teórica adotada e a metodologia empregada, a Modalidade parece ser mais expressiva nos painéis em comparação aos balões de fala, pois, como já observado, a Modalização e a Modulação não se realizam de modo tão expressivo nos trechos investigados quanto os Termos Básicos de Cores.

Encaminhamos neste momento para as considerações finais deste artigo.

\section{Considerações finais}

O objetivo do presente artigo foi analisar um excerto de Ms. Marvel, Volume 1: No Normal (2014), de G. Willow Wilson e Adrian Alphona, e suas traduções para o português brasileiro e o português europeu, sob a ótica da Estilística Tradutória, da Tradução Intermodal, da Linguística Sistêmico-Funcional e da Gramática do Design Visual. Além disso, utilizamos também a noção de Termos Básicos de Cores.

Ao iniciarmos a pesquisa, elencamos algumas perguntas que deveriam ser respondidas ao longo da análise. São elas: como se realiza a tradução interlinguística, principalmente no que diz respeito à metafunção interpessoal? Como a metafunção interpessoal é realizada no modo semiótico visual? Como os modos semióticos verbal e visual interagem do ponto de vista da metafunção interpessoal? E como a utilização de cores, no modo semiótico visual, auxilia na construção do significado do texto? Procuraremos, agora, tentar responder estas perguntas, de acordo com o que foi apresentado na seção de Resultados e Discussão.

A primeira pergunta trata da tradução interlinguística, enfocando a metafunção interpessoal. Podemos ver que não há variação nos papéis de fala (HALLIDAY; MATTHIESSEN, 2014; THOMPSON, 2014). Também podemos ver que tanto o textofonte quanto suas traduções para o português brasileiro e o português europeu 
apresentam um maior número de instâncias de Fornecimento. Isso ocorre pelo fato de o texto priorizar orações declarativas ao invés de outros tipos de orações.

A segunda pergunta trata da metafunção interpessoal em relação ao modo semiótico visual. Pode-se observar que os painéis analisados apresentam mais ocorrências de Oferta que de Demanda, como proposto por Kress e van Leeuwen (2006) com base em Halliday (1985). Assim, de forma alusiva à terceira pergunta, sob esse viés, o modo semiótico visual se assemelha ao modo semiótico verbal, pois o primeiro, como já dito, apresenta Ofertas mais recorrentemente e o segundo apresenta mais Fornecimento de mercadorias, recursos interpessoais esses que, em conjunto, podem impactar, visual e verbalmente, a leitora.

Por último, procuramos responder como o uso de cores auxilia na construção de significado do texto. Após a análise, podemos perceber que o Termo Básico de Cor mais utilizado é o vermelho. De acordo com van Leeuwen (2011), o uso de cores "quentes" como o vermelho, apresentam um significado de aproximação. No caso dos excertos analisados, o vermelho pode ter sido utilizado para, além de nos comunicar informações sobre a personagem, nos aproximarmos dela e de sua narrativa.

Esperamos ter colaborado para elucidar a relação entre os modos verbal e visual de um excerto de Ms. Marvel, Volume 1: No normal e suas respectivas traduções para o português brasileiro e o português europeu sob a égide da metafunção interpessoal.

\section{Referências Bibliográficas}

ALVES, D. A. S. Conflito e tradução: uma análise sobre as realizações linguísticas dos conflitos armados entre grupos litigantes no corpus paralelo Grande Sertão: Veredas - The Devil to Pay in the Backlands. 2014. 212f. Tese (Doutorado) - Programa de PósGraduação em Estudos da Tradução, Universidade Federal de Santa Catarina, Florianópolis, 2014.

ALVES, D. A. S.; ASSIS, R. C. Métodos de investigação em corpora: ferramentas para classificação de dados extraídos de corpora de pequenas dimensões para análises discursivas. In: ESCOLA BRASILEIRA DE LINGUÍSTICA COMPUTACIONAL, 8 \& 
ENCONTRO DE LINGUÍSTICA DE CORPUS, 13, 2015, João Pessoa. Anais... João Pessoa: UFPB, 2016, p. 1- 17. DOI https://doi.org/10.5151/sosci-viiieblc-xiii-elc04_artigo_01

BERLIN, B.; KAY, P. Basic color terms: their universality and evolution. Berkeley and Los Angeles: University of California Press, 1991.

BIGGAM, C. P. The semantics of colour: a historical approach. Cambridge: Cambridge University Press, 2015.

DINIZ, T. F. N. Literatura e cinema: da semiótica à tradução cultural. Ouro Preto: Editora UFOP, 1999.

DOLOUGHAN, F. J. Contemporary narrative: textual production, multimodality and multiliteracies. London and New York: Continuum, 2011.

FIGUEREDO, G. P. Introdução ao perfil metafuncional do português brasileiro: contribuições para os estudos multilíngues. 2011. 383 f. Tese (Doutorado) - Programa de Pós-Graduação em Estudos Linguísticos, Universidade Federal de Minas Gerais, Belo Horizonte, 2011.

HALLIDAY, M. A. K. An introduction to functional grammar. London: Arnold, 1985.

HALLIDAY, M. A. K.; MATTHIESSEN, C. M. I. M. An introduction to functional grammar. London: Arnold, 2004.

HALLIDAY, M. A. K.; MATTHIESSEN, C. M. I. M. Halliday's Introduction to Functional Grammar. London and New York: Routledge, 2014. DOI https://doi.org/10.4324/9780203783771

KARATZA, S. Analysing multimodal texts and test tasks for reading comprehension in the KPG exams in English. 2017. 562 f. Tese (Doutorado) - Curso de English Language and Literature, Philosophy, National and Kapodistrian University Of Athens, Athens, 2017.

KRESS, G. Literacy in the New Media Age. London and New York: Routledge, 2003. DOI https://doi.org/10.4324/9780203299234

KRESS, G. Multimodality: a social semiotic approach to contemporary communication. London and New York: Routledge, 2010. 
KRESS, G.; van LEEUWEN, T. Reading images: the grammar of visual design. London and New York: Routledge, 2006. DOI https://doi.org/10.4324/9780203619728

MALMKJAER, K. Translational stylistics: Dulcken's translations of Hans Christian Andersen. Language and Literature. London, v. 13 (1), p. 13-24, 2004. DOI https://doi.org/10.1177/0963947004039484

MALMKJAER, K. What happened to God and the angels: an exercise in translational stylistics. Target, Amsterdam, v. 15, p. 37-58, 2003. DOI https://doi.org/10.1075/target.15.1.03mal

MARTIN, J. R.; ROSE, D. Working with discourse: meaning beyond the clause. London and New York: Continuum, 2007.

MOYA GUIJARRO, A. J. M. A multimodal analysis of picture books for children: a systemic functional approach. Bristol: Equinox Publishing, 2014.

PAGANO, A. S.; SÁ, A. de M.; FERREGUETTI, K. A equivalência tradutória de Partículas Modais: um estudo baseado em corpus. Letras \& Letras, Uberlândia, v. 30, n. 2, p. 322-348, 2014. DOI https://doi.org/10.14393/LL60-v30n2a2014-15

SENDAK, M. Where the wild things are. London: Red Fox, 2007.

SPIVAK, G. Pode o subalterno falar? Tradução de Sandra Regina Goulart Almeida, Marcos Pereira Feitosa e André Pereira Feitosa. Belo Horizonte: Editora UFMG, 2010.

SUTROP, U. Towards a semiotic theory of basic colour terms and the semiotics of Juri Lotman. In: BIGGAM, C. P. et al (ed.). New directions in colour studies. Amsterdam and Philadelphia: John Benjamins Publishing Company, 2011. p. 39-48. DOI https://doi.org/10.1075/z.167.07sut

THOMPSON, G. Introducing Functional Grammar. London and New York: Routledge, 2014. DOI https://doi.org/10.4324/9780203785270

TOURY, G. Descriptive translation studies and beyond. Amsterdam and Philadelphia: John Benjamins, 1995. DOI https://doi.org/10.1075/btl.4

van LEEUWEN, T. The language of colour: an introduction. London and New York: Routledge, 2011. 
WILSON, G. W. et al. Ms. Marvel/Volume 1: No Normal. New York: Marvel Comics, 2014.

WILSON, G. W. et al. Ms. Marvel/Volume 1: Nada normal. Tradução de Rodrigo Barros e Paulo França. Barueri: Panini Comics, 2015.

WILSON, G. Willow et al. Ms. Marvel/Volume 1: Fora do normal. Tradução de Bernardo Rodrigues. Maspalomas: G. FLOY STUDIO, 2018. 